\title{
AE Characteristics of Rockburst Tendency for Granite Influenced by Water Under Uniaxial Loading
}

\author{
Yihan Zhang, Ju Ma*, Daoyuan Sun, Lingyun Zhang and Yongchao Chen \\ School of Resources and Safety Engineering, Central South University, Changsha, China
}

In deep mining, granite is stored with high energy duing to its structural integrity and brittleness. Rock bursts usually occur because stress changes and mining disturbances during mining, which seriously threaten safe production. Focusing on the factor -waterwhich may reduce the brittleness and rockburst tendency of granite, this work discussed the brittleness index and AE characteristics of dry and saturated water granite samples under uniaxial loading. The results show that the peak strength and elastic modulus of the saturated water granite are reduced. The damage degree of the water sample is larger than that of the dry sample, and the brittle failure is significantly reduced. The cumulative number of acoustic emission (AE) events in saturated water granite is significantly reduced compared to the dry sample, which is a decrease of $31.5 \%$. However, AE event rate is higher than that of dry granite in the late loading period; $A E$ quiet period of saturated water granite lasts longer and is more obvious than that of dry granite. Dry granite stores and releases more energy during the whole loading process, and the proportion of high energy level AE events in the later stage of loading is higher. The $b$ value of the two samples show a downward trend with fluctuation in the critical state of fracture and a jump increases at the moment of instability. The decrease of $b$ values of dry granite is larger than that of saturated water granite. Results suggest that the decline of $A E b$ value of granite can be taken as the precursor of rock burst, and water can significantly reduce the rockburst tendency of granite.

Keywords: water, rock, AE, $b$ value, rockburst tendency

\section{INTRODUCTION}

The stress environment of underground rock mass engineering is complicated and the elastic energy accumulated in the rock mass is released in the form of elastic wave due to mining activities and frequent microseismicity breaking stress balance, which is accompanied by the change of rock mass structure and even instability (Zhao et al., 2015; Dong et al., 2018; Peng et al., 2020). The acoustic emission (AE) signal of rock contains a lot of information about the damage evolution process of rock mass, which is used to study the failure process of rock mass and explore the effective precursor characteristics of rock mass instability. Since Goodman (1963) discovered the AE Kaiser effect in rock materials in 1963, many scholars have conducted a large number of laboratory experiments on the $\mathrm{AE}$ phenomenon generated by the process of rock fracture and failure.

The macroscopic failure of rock material is the result of the agglomeration of micro-fractures and the generation and expansion of large cracks (Peng et al., 2019). The temporal parameters 
and spatial distribution of $\mathrm{AE}$ reflect the spatio-temporal evolution characters of internal damage. Under the uniaxial compression experiment, a variety of $\mathrm{AE}$ characteristic parameters (Rudajev et al., 2000; Zhang et al., 2019) were used to comprehensively analyze the AE evolution of different types of rock (Naoi et al., 2018; Sirdesai et al., 2018), and the precursor of rock failure (Zhang Y. B. et al., 2015) has been discussed. Related researches (Zhao et al., 2008; Li et al., 2016) on $\mathrm{AE}$ precursor before rock failure pointed out the existence of an objective phenomenon of $\mathrm{AE}$ quiet period in rock $\mathrm{AE}$ experiments. The spatial distribution characteristics of $\mathrm{AE}$ are studied by using AE source localization algorithm, and the results of $\mathrm{AE}$ source localization can better reflect the direction and process of crack propagation and nucleation. In the uniaxial compression experiment of pre-set crack rock samples (Zhao et al., 2006), rock samples with natural fractures of different spatial combination types (Single type, parallel type, cross type, and mixed type) (Pei et al., 2013), and complete rock samples, the existing algorithm is used to reflect the spatio-temporal evolution of cracks and demonstrate the accuracy of AE location. The researches show that the AE localization results basically correspond to the actual damage. At the same time, the $\mathrm{AE}$ source localization method overcomes factors such as the pre-determined wave velocity (Dong et al., 2011) and the wave's propagation path (Hu and Dong, 2019) as a straight line in the update iteration to achieve high-precision positioning for complex spatial structures (Dong et al., 2020a,b). In order to meet the stress environment in which deep rock masses are located, carrying out laboratory AE experiments under complex stress paths (Du et al., 2016) provides a more effective ground reference value for engineering practice. Meng et al. (2016) analyze the laws of AE and energy conversion in uniaxial loading and unloading experiments of sandstone at different loading rates. Chmel and Shcherbakov (2013) compared the AE characteristics of granite under compression and impact failure. Since the $b$ value analysis, which originated from the seismological research, was introduced into the laboratory-scale AE research, a lot of discussions have been made on the improvement of algorithms, the influencing factors, and the changes in the $b$ value in the process of rock mass instability and failure. It is a consensus that the brittleness rock mass failure is accompanied by the decline of $b$ value, but the change of $b$ value before rock failure of different lithology is different. The $b$ value of salt rock, which is plastic rock, rises later in loading (Zhang Z. P. et al., 2015). The dynamic evolution characteristics of $b$ value of $\mathrm{AE}$ during rock failure can indicate that the crack inside the rock is expanding suddenly or gradually (Zeng et al., 1995). The decrease in shale $b$ value under complex stress paths only occurs when the stress exceeds $80 \%$ of the peak strength, and has nothing to do with bedding planes and loading paths (Wang and Xiao, 2018). Ge and Sun (2018) have studied the effect of heating and cooling conditions on the $b$ value, and considered that the $b$ value increases with the increase of heating and cooling cycles.

Water plays an important role in the geological disasters of rock engineering, and the micro-crack and the pore in rocks generally become the storage space of water. The original internal structure of rock will be changed by water in the process of complex physical (Zhao et al., 2017), chemical, and mechanical action. The rock will soften in different degrees, and its brittleness and strength will be reduced compared with the dry state (Vásárhelyi and Ván, 2006; Liu et al., 2012). The AE characteristics of water rock also show differences. Some scholars have carried out a lot of experimental research on the AE characteristics of rock affected by water. The effects of water in the quiet period of granite were compared from the perspective of $\mathrm{AE}$ energy rate and events. The same law was found in the $\mathrm{AE}$ experiments of limestone and siltstone under uniaxial compression. As the water content increased, the AE activity showed a downward trend in turn (Chen et al., 2017, 2018). Guo et al. (2018) compared the AE counts and energy changes of igneous rocks with different water contents under cyclic loading and unloading. Liu et al. (2018) carried out a research on AE characteristics of water-absorbing shale under uniaxial compression experiments, and found that water absorption stimulated the occurrence of $\mathrm{AE}$ events inside the shale and the $b$ value is higher. Wang et al. (2017) carried out uniaxial and triaxial compression $\mathrm{AE}$ experiments on saturated karst limestone, and discussed the effect of confining pressure on AE activities. However, research on the effect of water on the $b$ value of brittle rock masses is still insufficient. It is necessary to continue to explore the influence of water on the AE characteristics and $b$ value of granite combined with the fracture tendency of brittle rock masses. The differences of mechanical properties and AE characteristics between saturated water granite and dry granite under uniaxial compression are compared in this paper. The effect of water on the activity and $b$ value of $\mathrm{AE}$ events during rockburst incubation was emphatic discussed. It is of great theoretical significance and engineering application value to study the change of the mechanical strength characteristics and the rockburst tendency of granite as a typical brittle rock mass after hydration combined with AE technology.

\section{EXPERIMENT AND METHOD}

\section{Rock Samples}

The cuboid samples of granite with the size $50 \mathrm{~mm} \times 50 \mathrm{~mm} \times 100 \mathrm{~mm}$ and $100 \mathrm{~mm} \times 100 \mathrm{~mm} \times 200 \mathrm{~mm}$ were used to perform experiments. The surface of the rock sample was polished to ensure that its parallelism, flatness and perpendicularity to meet the ISRM recommendations. To reduce the differences among samples as much as possible, same size samples were obtained from one granite. Dry and saturated water granite rock samples were set in the experiment. The dry rock samples were placed flat in a water tank, and water was first added to $1 / 4$ of the height of the experiment piece. Water was added at intervals of $2 \mathrm{~h}$, until the rock sample was completely immersed in water. The samples were taken out after $12 \mathrm{~h}$ and made into water rock samples. It is important to emphasize that all $\mathrm{AE}$ data except for $\mathrm{AE}$ localization data are from the $50 \mathrm{~mm} \times 50 \mathrm{~mm} \times 100 \mathrm{~mm}$ sample. Since the sensor inevitably fell off during the experiment, AE events with less than 5 hit signals could not be located efficiently. To perform AE localization, we also carried out the experiment with the same 
conditions on the $100 \mathrm{~mm} \times 100 \mathrm{~mm} \times 200 \mathrm{~mm}$ sample using the Vallen 32-channel AE monitoring equipment.

\section{Experimental Instruments}

The experimental instruments included two parts: stress loading equipment and $\mathrm{AE}$ monitoring system (Figure 1). The loading equipment was the MTS322 material test system (load the $50 \mathrm{~mm} \times 50 \mathrm{~mm} \times 100 \mathrm{~mm}$ sample) and the MTS815 Flex test GT rock mechanics test system (load the $100 \mathrm{~mm} \times 100 \mathrm{~mm} \times 200 \mathrm{~mm}$ sample), which performed the static, dynamic, normal temperature, high temperature, high pressure, and failure mechanics experiments of brittle materials such as rock and concrete. It recorded load, stress, displacement and strain values in real time, and simultaneously draws loaddisplacement, stress-strain curves. The PCI-2 AE equipment from the PAC Company in the United States was used to collect the AE data of the $50 \mathrm{~mm} \times 50 \mathrm{~mm} \times 100 \mathrm{~mm}$ sample. The sensor was NANO30 resonant sensor with a center response frequency of $125 \mathrm{kHz}$. AE monitoring system used in the $100 \mathrm{~mm} \times 100 \mathrm{~mm} \times 200 \mathrm{~mm}$ sample was the AMSY-6 multichannel equipment from Vallen, Germany (consisting of parallel measuring channels). AE characteristic parameters and waveform acquisition were synchronized during the experiment. The system was equipped with the highest international acquisition card. Each block had two independent channels. The channel ADC was $40 \mathrm{MHz}$, the accuracy was 18 bits, and the wideband operating frequency was $18 \mathrm{KHz}-2.4 \mathrm{MHz}$. VS45-H sensor was used in the experiment, and the response frequency of that was $40-450 \mathrm{KHz}$.

\section{AE Sensor Arrangement}

In the experiment, $6 \mathrm{AE}$ sensors and $32 \mathrm{AE}$ sensors were placed on the surface of the $50 \mathrm{~mm} \times 50 \mathrm{~mm} \times 100 \mathrm{~mm}$ and $100 \mathrm{~mm} \times 100 \mathrm{~mm} \times 200 \mathrm{~mm}$ samples, respectively, with an alternating dislocation arrangement to record the characteristic parameters and waveforms of the AE hits (Figure 1). Vaseline was applied to the contact area between the sample and the sensor to ensure the coupling effect, and the sensor was fixed with tape to avoid it falling off during the loading process. The pre-amplifier of the $\mathrm{AE}$ experiment and analysis system was set as $40 \mathrm{~dB}$, the threshold value was $50 \mathrm{db}$, and the sampling frequency was $10 \mathrm{MHz}$. Before the experiment, checked the installation of the specimen, the coupling degree of AE sensor and debugged the equipment.

\section{Experiment Procedure}

In order to avoid the influence of the noise generated by the contact between the rock sample and the pressure plate on the
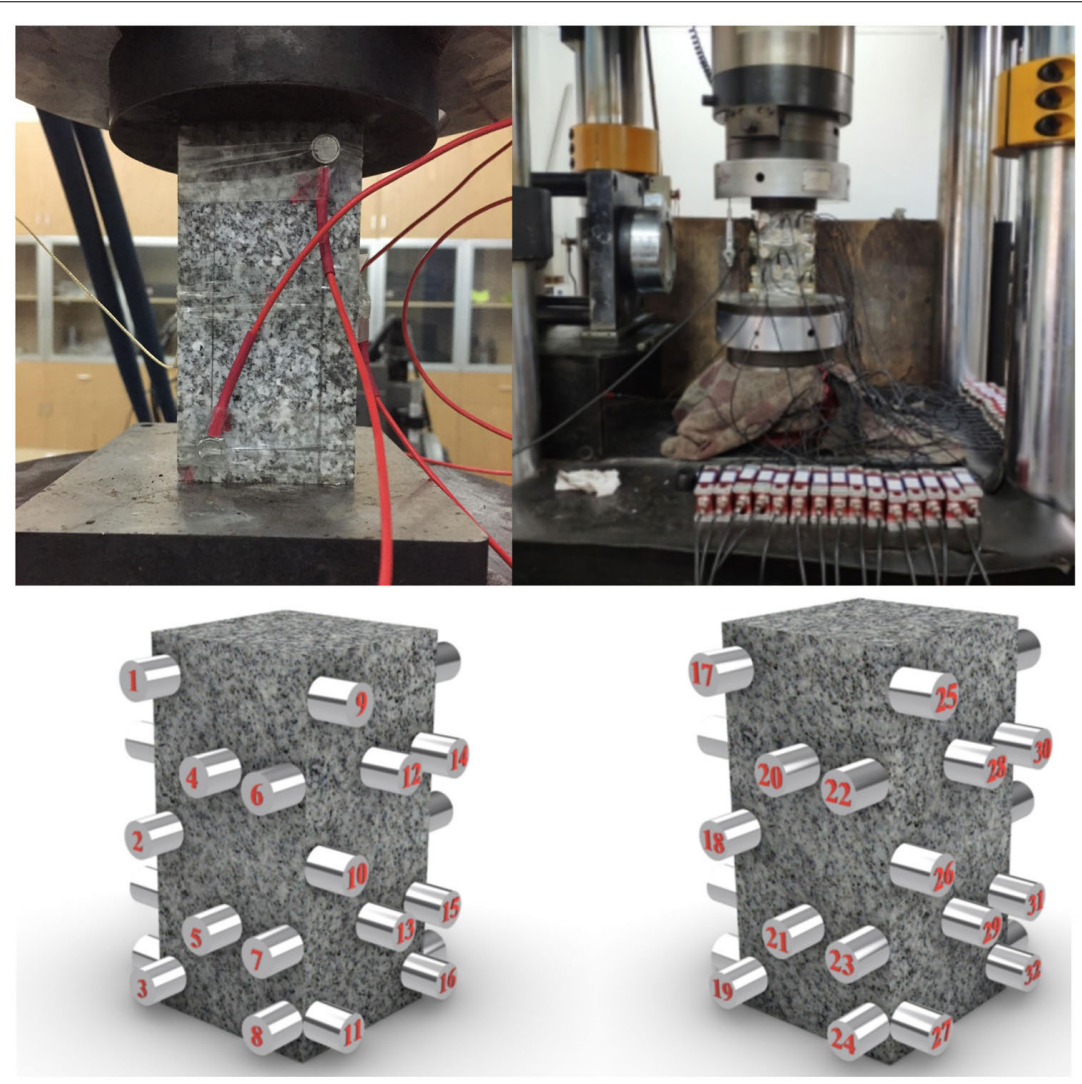

FIGURE 1 | Experimental instruments and Installation and distribution diagram of AE sensor (100 mm $\times 100 \mathrm{~mm} \times 200 \mathrm{~mm}$ sample). (Top Left) $50 \mathrm{~mm} \times 50 \mathrm{~mm} \times 100 \mathrm{~mm}$ sample under uniaxial compression experimental equipment. (Top Right) $100 \mathrm{~mm} \times 100 \mathrm{~mm} \times 200 \mathrm{~mm}$ sample under uniaxial compression experimental. (Bottom) The sensors arranged on two parallel sides are misaligned to reduce duplication of arrival time data for AE source location. 
results of $\mathrm{AE}$ monitoring, the rock sample was placed on the loading device in advance to load $1 \sim 2 \mathrm{kN}$ to make the rock sample fully contact the reinforced plate. Granite was loaded by controlled force during uniaxial compression experiment. The loading rate set in the experiment was $40 \mathrm{kN} / \mathrm{min}$. During the experiment, ensured the synchronization of the loading experiment system and the $\mathrm{AE}$ monitoring system, and recorded the experiment data in real time. After loading the rock sample to the peak strength, the experiment ended.

\section{CALCULATION METHOD OF $b$ VALUE BASED ON AE EVENT}

In the method of calculating $b$ value of rock $\mathrm{AE}$, the magnitude in the G-R relationship is usually replaced by the magnitude and energy of the AE hit. Since the noise signal was doped, the $b$ value calculated by the $\mathrm{AE}$ hit recorded by a single sensor could not accurately reflect the rock variation characteristics (Figure 2). So the calculation method of $b$ value is given first. In the experiment, when an $\mathrm{AE}$ hit signal generated by an $\mathrm{AE}$ source was detected by multiple sensors simultaneously, it was recorded as an $\mathrm{AE}$ event. We defined the absolute energy and absolute amplitude of the $\mathrm{AE}$ event as the maximum value of the energy or amplitude of multiple $\mathrm{AE}$ hits corresponding to an $\mathrm{AE}$ event. The average energy and average amplitude of the AE event were the average value of the energy or amplitude of multiple $\mathrm{AE}$ hits. Both the amplitude and energy of $\mathrm{AE}$ were used to characterize the strength of a rock fracture, which was equivalent to the physical significance of the magnitude. Therefore, the maximum amplitude, maximum energy, average amplitude, and average energy of the $\mathrm{AE}$ event were used to calculate the $b$ value. In order to standardize $\mathrm{AE}$ to earthquake, the magnitude of $\mathrm{AE}$ event is divided by $20(\mathrm{~A} / 20)$ and the energy of $\mathrm{AE}$ event is taken as $\operatorname{logarithm}(\lg E)$ to represent the magnitude of $\mathrm{AE}$ source (Chmel and Shcherbakov, 2014; Liu et al., 2017; Sagasta et al., 2018; Dong and Zhang, 2019). The correction formula calculated by least squares can be expressed as Eq. 1 and Eq. 2:

$$
\lg N(A / 20)=a-b(A / 20)
$$

$$
\lg N(\lg E)=a-b \lg E
$$

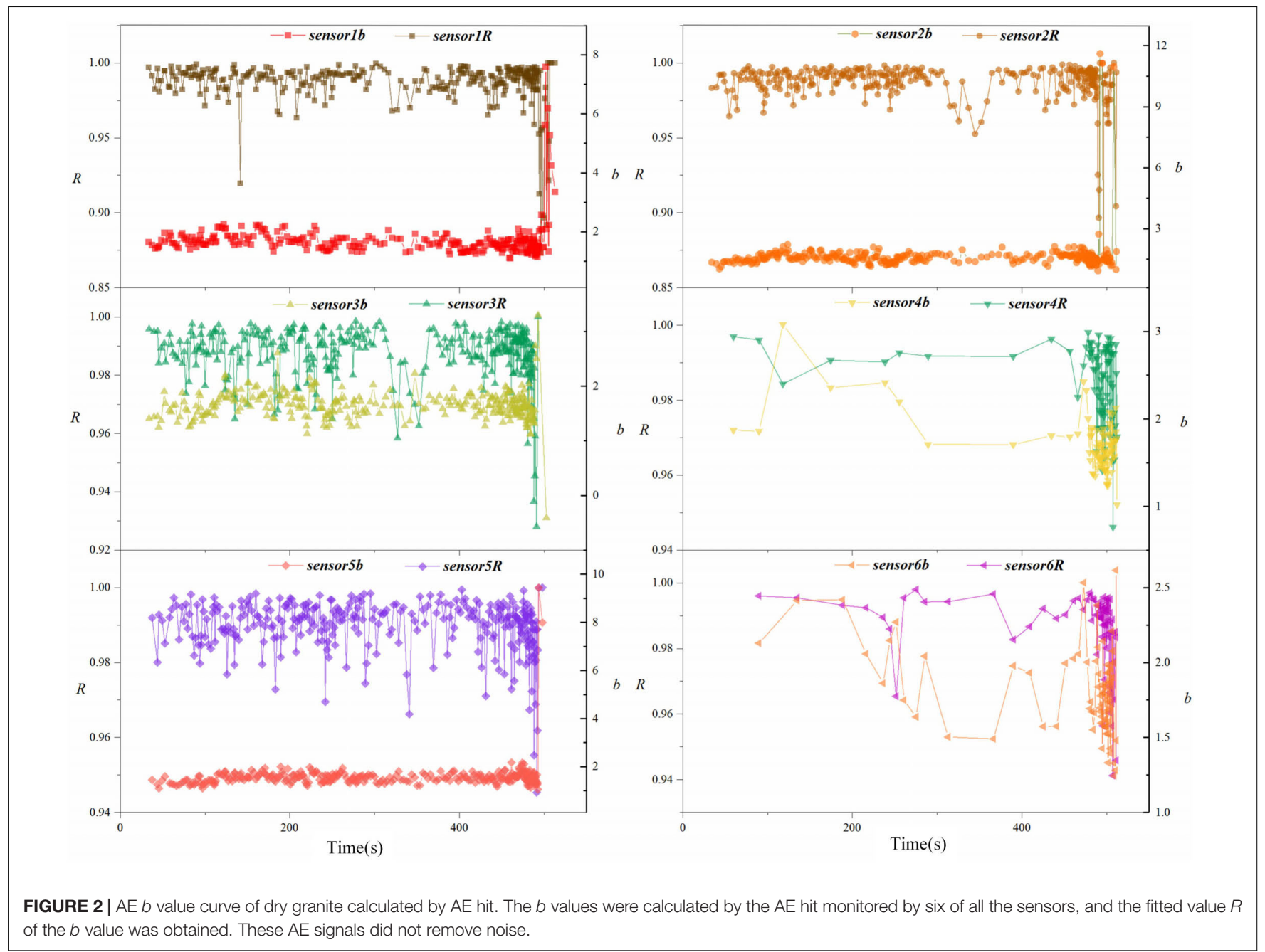


Each time $b$ value was calculated using $200 \mathrm{AE}$ events as the sampling window, then $100 \mathrm{AE}$ events were used as the step size to slide in time and repeatedly calculate the $b$ value. Furthermore, the variation of $b$ value calculated by 4 parameters of granite with time under uniaxial compression was obtained.

\section{RESULTS AND DISCUSSION}

\section{The Change of $b$ Value}

Acoustic emission $b$ value is used as a measure to characterize the development of cracks. The change of $b$ value corresponds to the fluctuation of the proportion of large and small AE events in the rock, that is, the trend of crack development at different scales. The trend of $b$ value can indicate that the crack inside the rock is expanding suddenly or steadily. When the $b$ value fluctuates steadily, the proportion of large and small AE events is basically maintained at a stable level, and microcracks with different internal scales develop stably. Large fluctuation of $b$ values indicate a sudden burst of crack growth. The decrease of the $b$ value before failure indicates that there are more largescale AE events, and the cracks accelerate and penetrate (Rao and Lakshmi, 2005; Zhang and Zhang, 2017).

The $4 b$ values are calculated using the maximum amplitude, average amplitude, maximum energy, and average energy of $\mathrm{AE}$ events, respectively. During the fracture of dry and saturated water granite under uniaxial compressive load, the changes of 4 $b$ values with stress and strain are basically consistent (Figures 3, 4). After the start of loading, the $b$ value is at a relatively high level relative to the whole loading process, showing a downward trend with fluctuation; It reflects that small-scale cracks dominate in the initial stage and a large number of new cracks are generated with the progress of loading; Since the scale of the new crack is larger than the original crack that is compacted, the proportion of large $\mathrm{AE}$ events gradually increases and micro-fractures inside the rock gather together; The crack development in the rock shows a steady expansion. When granite approaches instability, the $b$ value fluctuates greatly and reaches its minimum; The clustering of the large AE events is apparent in the process, and a large number of cracks of different scales start to spread suddenly and penetrate each other. When the granite reaches the peak stress, the $b$ values rise sharply and reach high values, and the local rock mass is crushed at rockburst moment, causing severe damage. It may be because the sensor and the rock poor coupling or even falling off causes loss of rock fracture signal due to the volume expansion effect. Therefore, the signals in the moment of failure cannot objectively reflect the truth of the size of AE event. Granite, as a typical brittle rock, is sensitively affected by the difference in the degree of development of internal joint fractures. Large change in $b$ value reflects dramatic changes in crack growth;
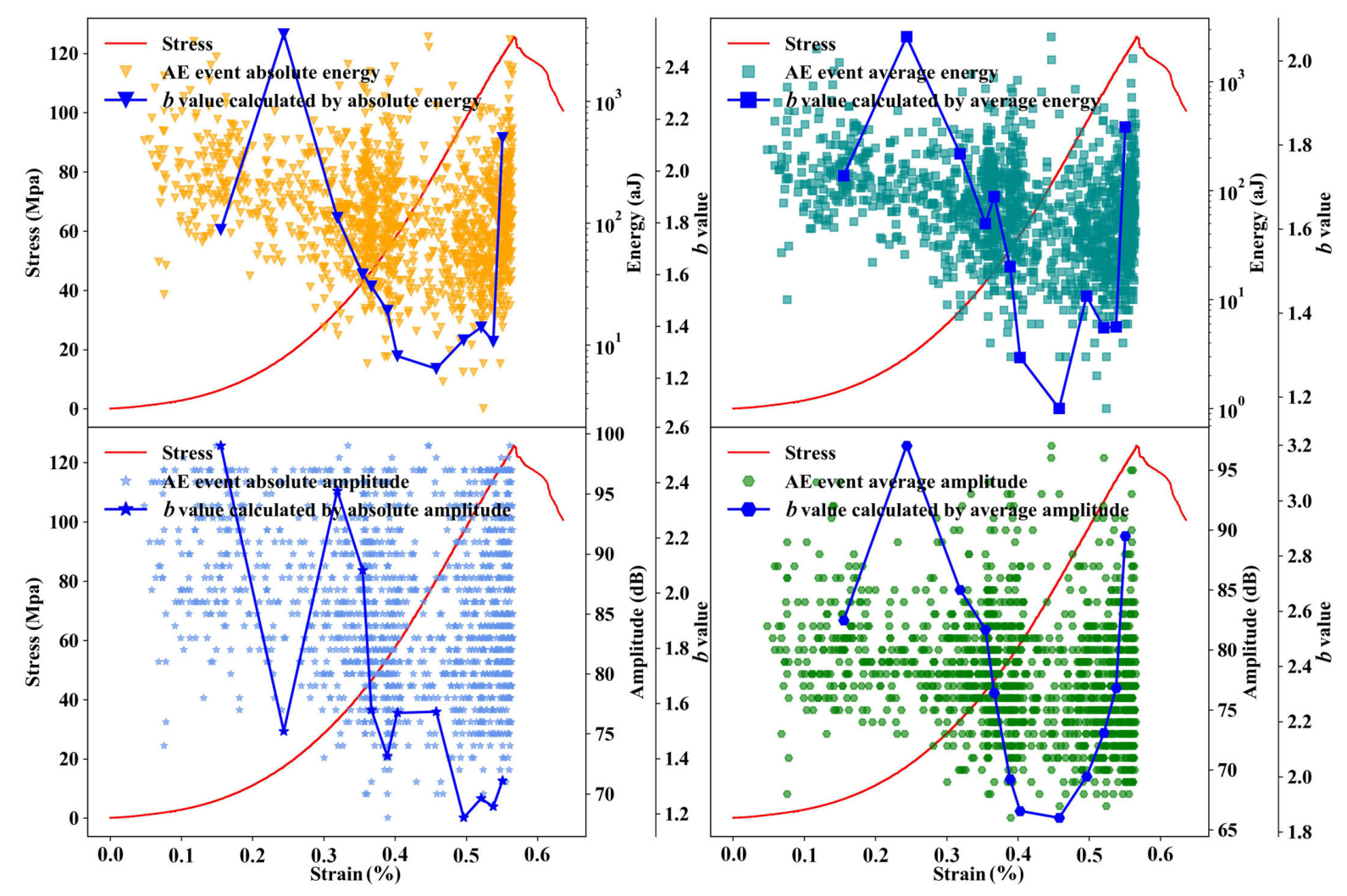

FIGURE 3 | The variation in 4 AE $b$ values (blue point-line) of dry granite versus strain under uniaxial compression. The distribution characteristics of the absolute amplitude (blue point), absolute energy (orange point), average amplitude (cyan point), and average energy (green point) of the AE event show good consistency with the fluctuation of the $b$ value. 


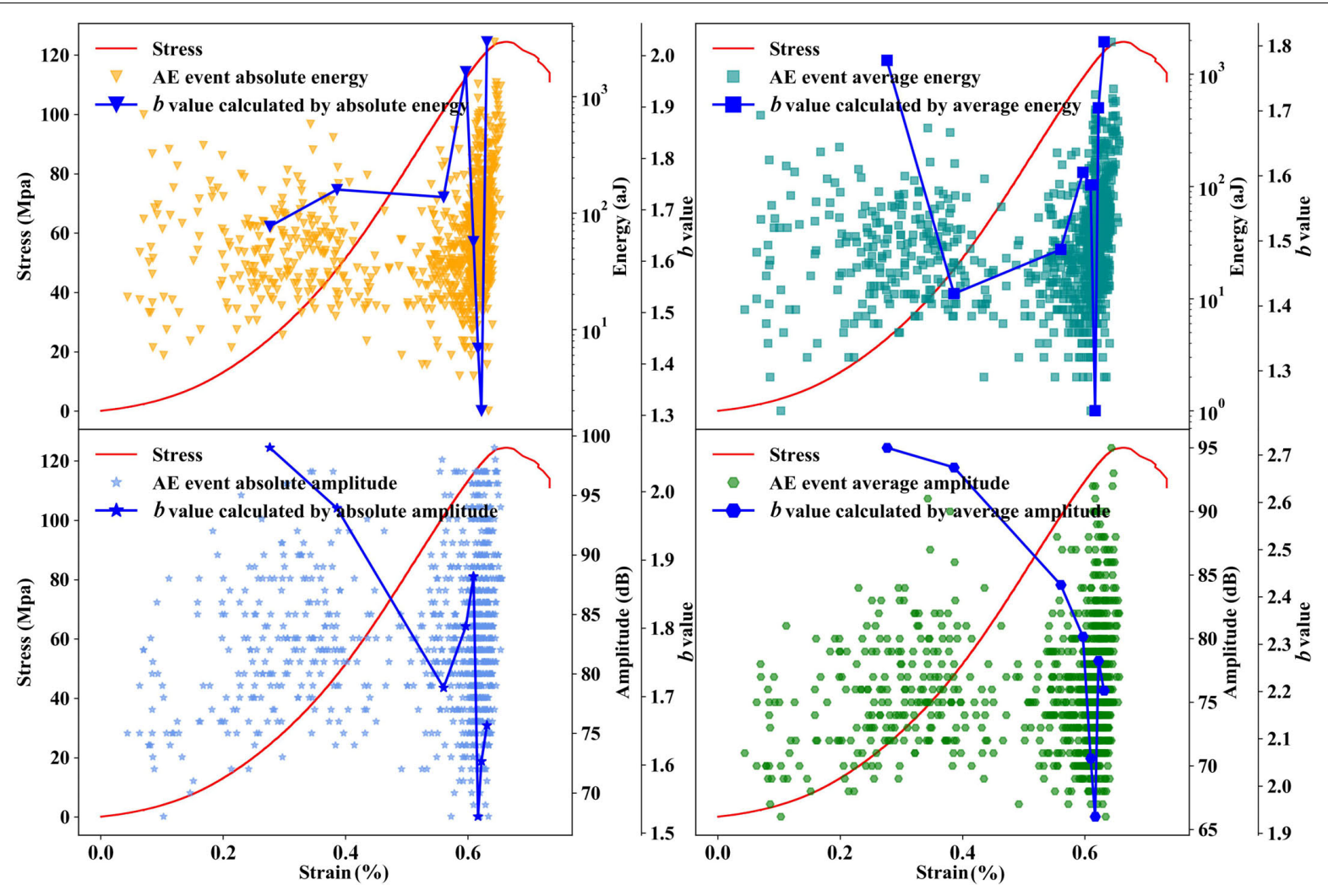

FIGURE 4 | The variation in 4 AE $b$ values (blue point-line) of saturated water granite versus strain under uniaxial compression. The distribution characteristics of the absolute amplitude (blue point), absolute energy (orange point), average amplitude (cyan point), and average energy (green point) of the AE event show good consistency with the fluctuation of the $b$ value.

The critical state of the rock will cause stress concentration at the end of the large-scale crack that has been formed, and a series of diffusive microcracks will be generated around the large crack; Collapse occurs in fragile local or adjacent large cracks causing significant volume response.

Compared with dry granite, the minimum value of $b$ value is larger and the maximum value of $b$ value is smaller in saturated water granite. The AE $b$ value of the saturated water granite has a relatively gentle downward trend, with a decrease in $b$ value between 0.7 and 1 . The microcracks in water rock are stable and slow. The large-scale cracks continue to accumulate steadily and the proportion of large-scale cracks gradually increase (Figure 4). The $b$ value of dry granite fluctuates violently during this process, with a larger and more rapid decline. The difference in $b$ value reach 1.5. It reveals that the scale of the microfracture inside the rock changes significantly, and large-scale cracks expand more fully, showing a state of rapid expansion (Figure 3). The pore water filling reduces the friction caused by rock compaction, and the fissure water filling is easy to further expand the original cracks, reflecting that the $b$ value of the saturated water granite in the early stage of loading is smaller. Due to the stress corrosion and pressure dissolution of water on rocks at the later stage of loading (Li et al., 2010), the proportion of small-scale cracks is higher, and the $b$ value is higher than that of dry granite.
The variation characteristics of $b$ value under uniaxial loading indicate that the internal micro-fracture state of dry granite changes sharply during loading, and the internal fracture degree of damage is more sufficient. The existence of water makes the crack growth trend of granite gentle, the rock appears to soften, plastic enhancement, and weaken rockburst tendency.

\section{The Change of AE Energy}

Energy distribution and cumulative process of AE events during uniaxial loading are used to evaluate the effect of water on the tendency of granite rockburst (Figures 5, 6). The AE energy released by microfractures in rocks is proportional to the scale of crack propagation. The size of AE energy characterizes the size of microfractures in rocks. From the perspective of the release of AE energy, The energy release of dry granite remains active throughout the loading process, and the energy stored and released is much greater than that of saturated water granite. The energy released by granite throughout the fracture process is significantly reduced by water. With the increase of the axial load, the accumulation of AE energy is almost stagnant, corresponding to the quiet period of the AE event. AE energy of saturated water granite increases exponentially before rupture. From the perspective of $\mathrm{AE}$ energy level distribution, the proportion of $\mathrm{AE}$ events with high energy level which is above $10^{3}$ accounts for $44.9 \%$ in the crack propagation stage before dry granite failure 


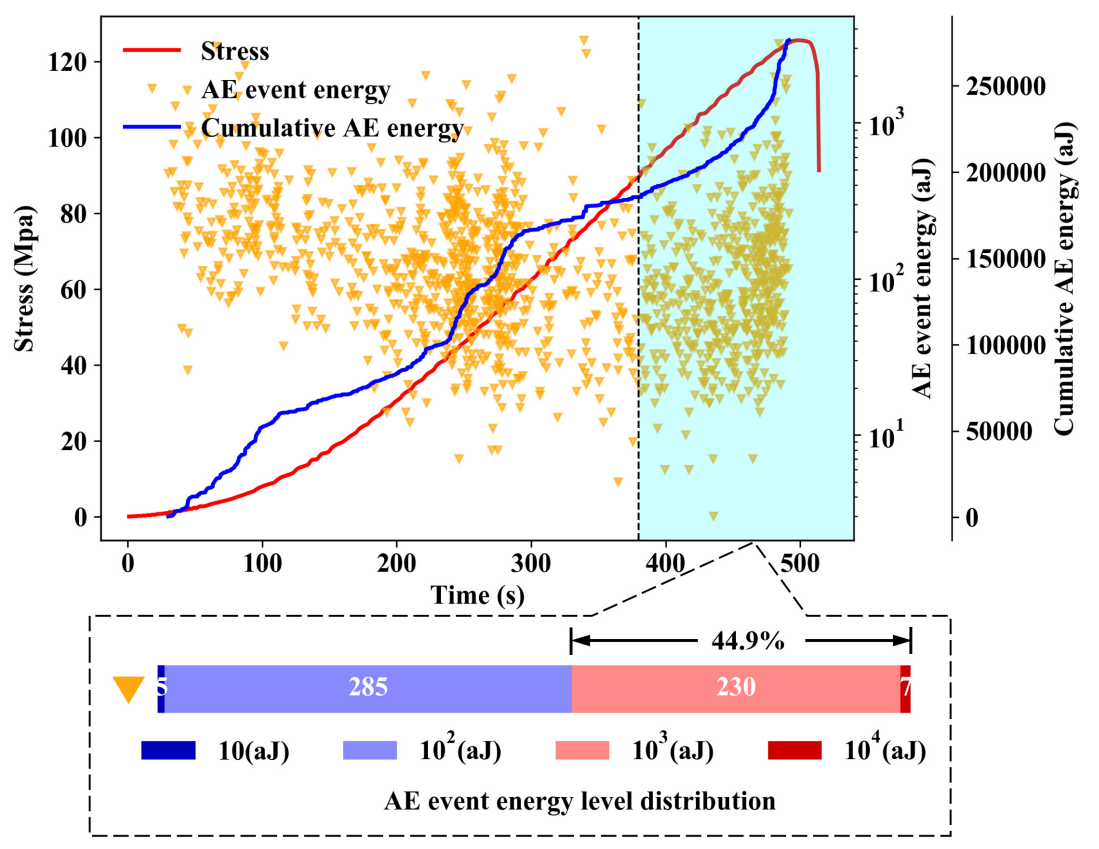

FIGURE 5 | Evolution and distribution of AE events energy versus time in dry granite. The crack propagation phase corresponds to the concentrated release of energy (highlighted area), and high energy level acoustic emission events account for $44.9 \%$. AE sources tend to fracture more violently in critical state of rock burst.

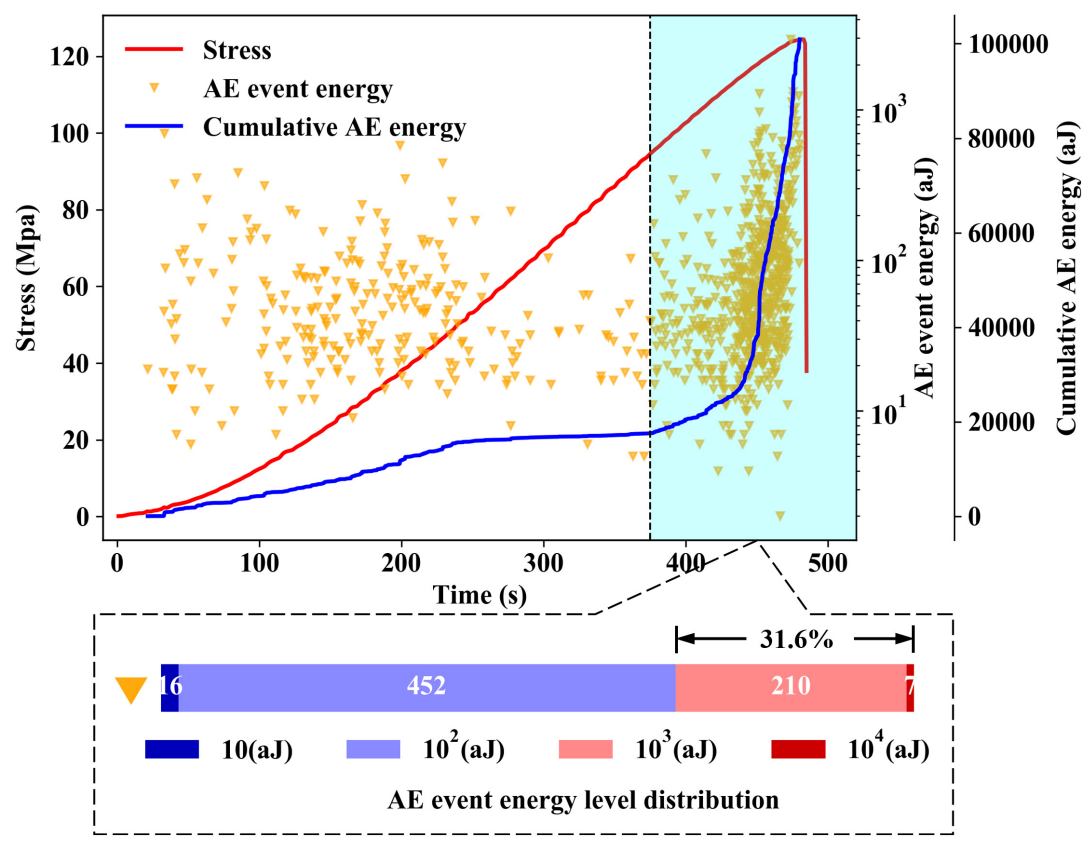

FIGURE 6 | Evolution and distribution of AE events energy versus time in saturated water granite. The crack propagation phase corresponds to the concentrated release of energy (highlighted area), and high energy level acoustic emission events account for $31.6 \%$. AE sources tend to fracture more gently in critical state of rock burst.

(Figure 5). Saturated water granite produce more AE events before failure, but the energy level of AE events are distributed at lower levels, and AE events with energy levels above $10^{3}$ accounts for $31.6 \%$ (Figure 6).
On the one hand, the crystal grains inside the rock are softened by water and the bonding between the particles is weakened, which inhibits the release of energy during rock fracture. On the other hand, water reduces the 


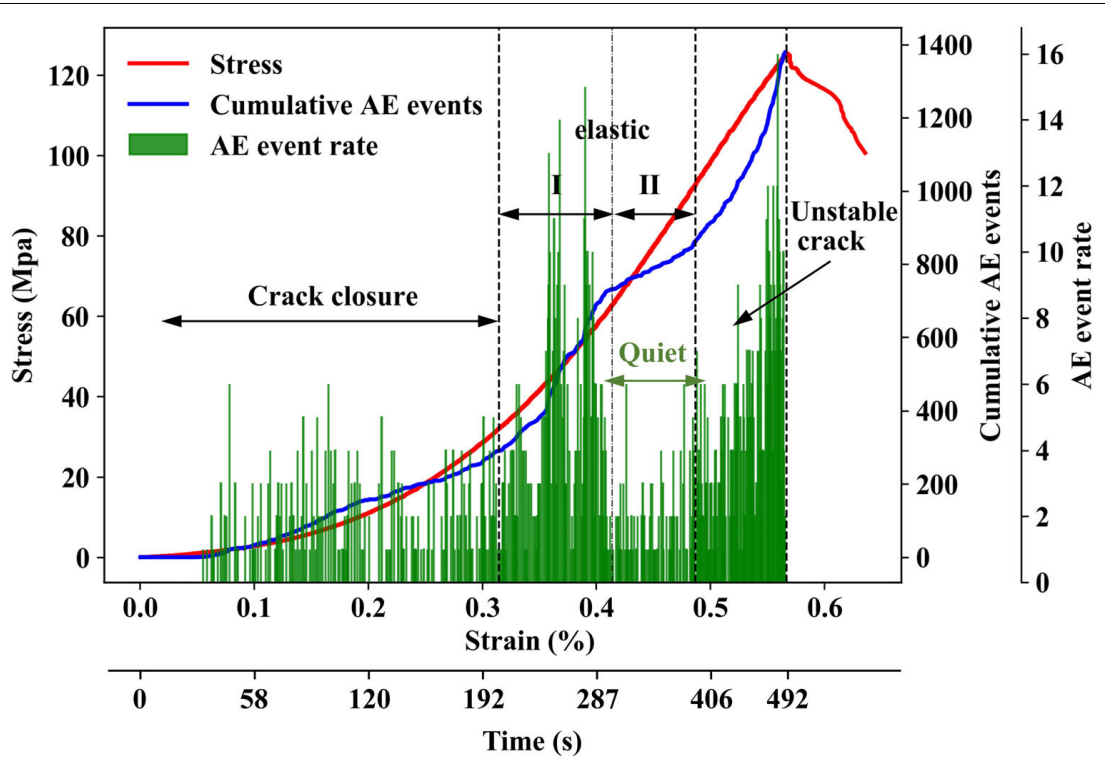

FIGURE 7 | Damage evolution of granite on time and strain scales under uniaxial compression in dry state. Divides the different stages of the uniaxial compression process according to the AE characteristics and stress-strain.

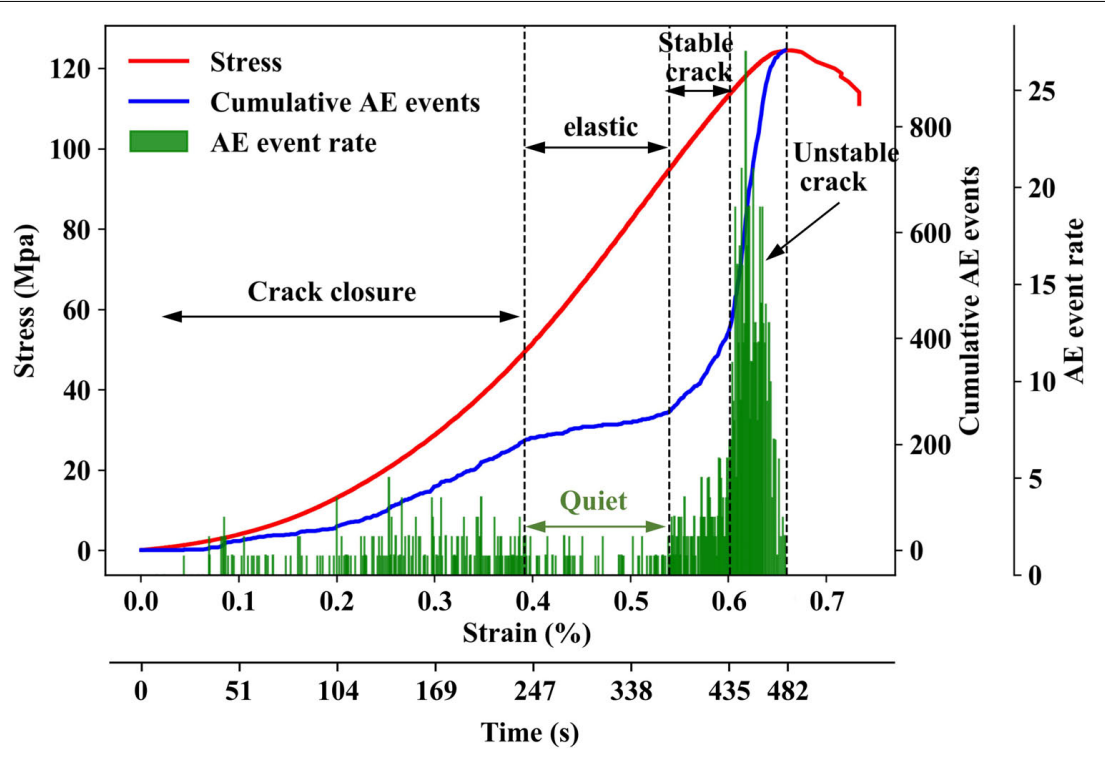

FIGURE 8 | Damage evolution of granite on time and strain scales under uniaxial compression in water state. Divides the different stages of the uniaxial compression process according to the AE characteristics and stress-strain.

TABLE 1 | comparison of AE event characteristics between dry and saturated water granite.

\begin{tabular}{|c|c|c|c|c|c|c|c|}
\hline Sample & $\begin{array}{l}\text { Cumulative } \\
\text { AE events }\end{array}$ & $\begin{array}{l}\text { Loading } \\
\text { time (s) }\end{array}$ & $\begin{array}{l}\text { Quiet period } \\
\text { duration (s) }\end{array}$ & $\begin{array}{c}\text { Quiet period } \\
\text { duration ratio }(\%)\end{array}$ & $\begin{array}{l}\text { Initial stress in quiet } \\
\text { period } \sigma_{1}(\mathrm{MPa})\end{array}$ & $\begin{array}{c}\text { Peak stress } \sigma \\
\text { (MPa) }\end{array}$ & $\begin{array}{c}\text { The stress ratio } \\
\sigma_{1} / \sigma(\%)\end{array}$ \\
\hline Dry granite & 1378 & 492 & 84 & 17.0 & 61.661 & 125.571 & 49.1 \\
\hline Saturated water granite & 944 & 482 & 130 & 26.9 & 52.948 & 124.462 & 42.5 \\
\hline
\end{tabular}

threshold of internal fracture in the critical state of the rock, resulting in the generation of a large number of low energy level AE events. Due to the water rock interaction, the process of energy release is more peaceful when the instability occurs, which cause that the rockburst tendency is significantly reduced. 


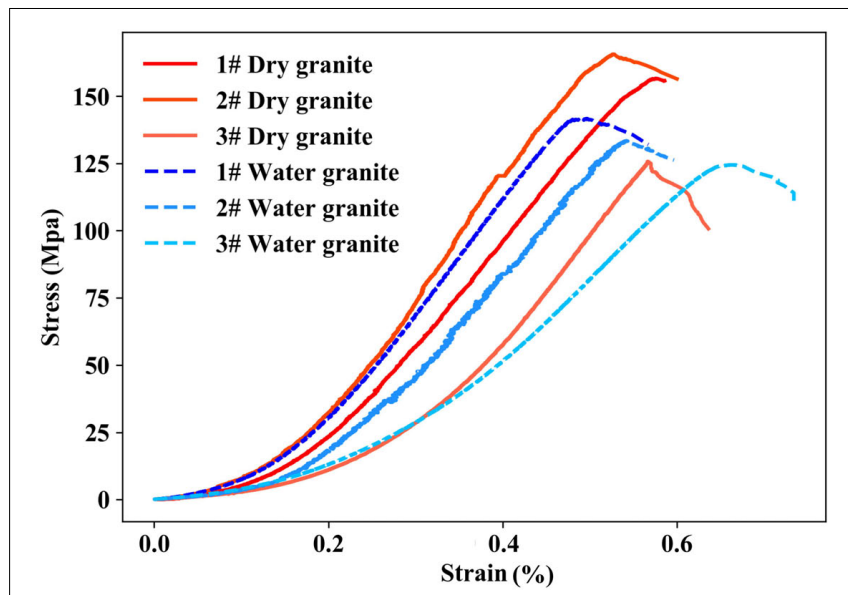

FIGURE 9 | Uniaxial compression stress-strain curve of dry (warm color) and saturated water granite (cool color) samples. Divides the different stages of the uniaxial compression process according to the AE characteristics.

TABLE 2 | Mechanical parameters of dry and saturated water granite.

\begin{tabular}{lccc}
\hline Sample & UCS (MPa) & Young modulus (Gpa) & Peak strain \\
\hline 1\# Dry granite & 165.835 & 43.087 & $5.25 \times 10^{-3}$ \\
2\# Dry granite & 156.842 & 37.834 & $5.72 \times 10^{-3}$ \\
3\# Dry granite & 125.571 & 36.726 & $5.65 \times 10^{-3}$ \\
Mean & 149.416 & 39.215 & $5.54 \times 10^{-3}$ \\
1\# Saturated water granite & 141.854 & 39.025 & $4.94 \times 10^{-3}$ \\
2\# Saturated Water granite & 133.861 & 33.215 & $5.39 \times 10^{-3}$ \\
3\# Saturated Water granite & 124.462 & 28.611 & $6.45 \times 10^{-3}$ \\
Mean & 133.392 & 33.617 & $5.59 \times 10^{-3}$ \\
\hline
\end{tabular}

\section{The Change of AE Events and Quiet Period}

Acoustic emission events can be used to capture and classify rock deformation and failure processes (Liu et al., 2018; Du et al., 2019). When the axial stress is small, a small number of $\mathrm{AE}$ events can be observed during the crack closing stage. With
TABLE 3 | Lumpiness statistics of dry and saturated water granite.

\begin{tabular}{lcccccc}
\hline Sample & \multicolumn{7}{c}{ Number of pieces } \\
\cline { 2 - 7 } & $\begin{array}{c}>\mathbf{5 0} \\
(\mathbf{m m})\end{array}$ & $\begin{array}{c}\mathbf{5 0 \sim 4 0} \\
(\mathbf{m m})\end{array}$ & $\begin{array}{c}\mathbf{4 0} \mathbf{3 0} \\
(\mathbf{m m})\end{array}$ & $\begin{array}{c}\mathbf{3 0 \sim 2 0} \\
(\mathbf{m m})\end{array}$ & $\begin{array}{c}\mathbf{2 0} \sim \mathbf{1 0} \\
(\mathbf{m m})\end{array}$ & $\begin{array}{c}<\mathbf{1 0} \\
(\mathbf{m m})\end{array}$ \\
\hline $\begin{array}{l}\text { Dry granite } \\
\begin{array}{l}\text { Saturated Water } \\
\text { granite }\end{array}\end{array}$ & 2 & 2 & 1 & 7 & 23 & neglect \\
& 2 & 2 & 3 & 4 & 16 & neglect \\
\end{tabular}

the increase of the axial load, stable crack propagation occurs in the rock, and the slope of the cumulative number of $\mathrm{AE}$ events almost remains constant. Unstable crack growth accompany by the exponential increase in the release of $\mathrm{AE}$ events, and the slope of the curve gradually increases, indicating that the rock is approaching failure.

It is similar for the trends of $\mathrm{AE}$ event rate and cumulative event at different Crack stage of dry and saturated water granites (Figures 7, 8). In the initial stage of loading, the original cracks of the granite are compacted, and both the dry and saturated water granite have $\mathrm{AE}$ phenomena, but the $\mathrm{AE}$ event rate of the dry granite is greater. As the internal micro-cracks of saturated water granite absorb water to fill the interstitial spaces, the existence of pore water pressure reduces the degree of microcracks being compacted, resulting in a reduction in $\mathrm{AE}$ event (Zhang et al., 2017). The AE quiet period that corresponds to the elastic stage occurs in both the dry and saturated water granites, and the $\mathrm{AE}$ event rate remains at a low level. The peak value of $\mathrm{AE}$ event rate in the elastic stage of dry granite (elastic I in Figure 7) may be influenced by Kaiser effect, and it is speculated that there may be defects or uneven distribution of particles in the rock, resulting in a significant change in the slope of stress-strain curve in the elastic stage. The dry granite enters the $\mathrm{AE}$ quiet period when the stress is loaded to $49.1 \%$ of the peak intensity, and the duration accounts for $17 \%$ of the whole loading process. The AE quiet period of the saturated water granite is more obvious. The AE quiet period of saturated water granite is more obvious. When the peak stress reaches $42.5 \%$, it enters the $\mathrm{AE}$ quiet period that the duration of accounts for $26.9 \%$ of the whole loading process. The quiet

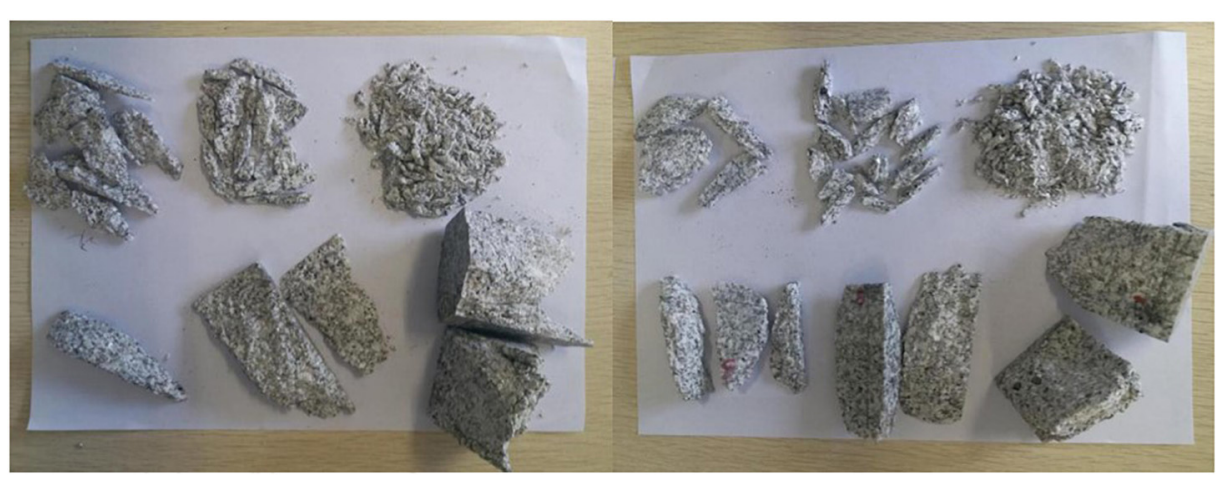

FIGURE 10 | Fracture status of granite after rockburst. (Left) Dry granite, (Right) Saturated water granite. The statistical results of the block degree are shown in Table 3. 
period of AE of dry granite has a short duration and a high stress level, while that of saturated water granite has a long duration and a low load level. When the crack expands rapidly and approaches failure, the $\mathrm{AE}$ event rate increases rapidly to the peak value, and the peak value of $\mathrm{AE}$ event rate of saturated water granite exceeds 25 , which is significantly higher than that of dry granite. This is because water can significantly reduce the threshold value of subcritical crack propagation in rocks, and water in a high stress state promotes the generation of microfracture and intensification of crack propagation (Wan et al., 2010; Hao et al., 2015). The cumulative AE events of dry granite and saturated water granite during the loading process are 1378 and 944, respectively. Compared with dry granite, the cumulative $\mathrm{AE}$ events of saturated water granite decrease by $31.5 \%$, and the $\mathrm{AE}$ activities of dry granite during the whole loading process are more intense (Table 1). To some extent, water as a whole inhibits the AE activity of granite but stimulates AE activity of granite under high pressure. We can consider that the internal fracture of granite is reduced and the loading capacity of granite is deteriorated.

\section{Analysis of Mechanical Properties}

The linear elastic deformation of dry granite is more significant and the peak strength is higher, while the saturated water granite shows obvious plasticity (Figure 9). The compressive strength of granite under different conditions is $149.416 \mathrm{MPa}$ and 133.392 MPa, respectively, and the uniaxial compressive strength of granite samples under dry conditions is higher. The average modulus calculated in this paper is the slope of the secant line at the two points on the stress-strain curve before the peak. The average modulus of dry granite is $39.215 \mathrm{Gpa}$ and that of saturated water granite is $33.617 \mathrm{Gpa}$ (Table 2). Due to the water content of granite, its peak strength and elastic modulus are reduced to a certain extent and the granite exhibits a significant ductility during loading. This weakens the damage of the water to the interior of the rock and promotes the growth of native cracks, causing the granite to yield the intensity and peak intensity decrease accordingly.

The distribution of the block size after the granite breaks directly reflects the degree of damage (Figure 10). The sieving method is used to calculate the sample size of the broken samples in the experiment. According to the actual fracture characteristics of the rock samples, the average value of the three-dimensional length of the fragments is taken, and the 6 intervals $(>50 \mathrm{~mm}$, 50-40 mm, 40-30 mm, 30-20 mm, 20-10 mm, and <10 $\mathrm{mm}$ ) are divided by $10 \mathrm{~mm}$ intervals. The number of fragments is statistically classified in the interval. For over-broken pieces with block size less than $10 \mathrm{~mm}$, the statistical significance is not obvious and ignored.

There are 35 pieces of dry granite larger than $10 \mathrm{~mm}$, while 27 pieces of saturated water granite are larger than $10 \mathrm{~mm}$. In the interval below $30 \mathrm{~mm}$, the number of dry granite is more than that of saturated water granite. It is more sufficient for the fracture degree of dry sample indicate that the uniaxial compression cracking is more significant. It is consistent with the analysis conclusion of AE characteristics. The degree of granite fragmentation is positively correlated with the magnitude of the change in $b$ value. The fractured degree of the saturated water granite is low, and the more large pieces are retained, which corresponds to less accumulated AE events and energy release during the loading process.
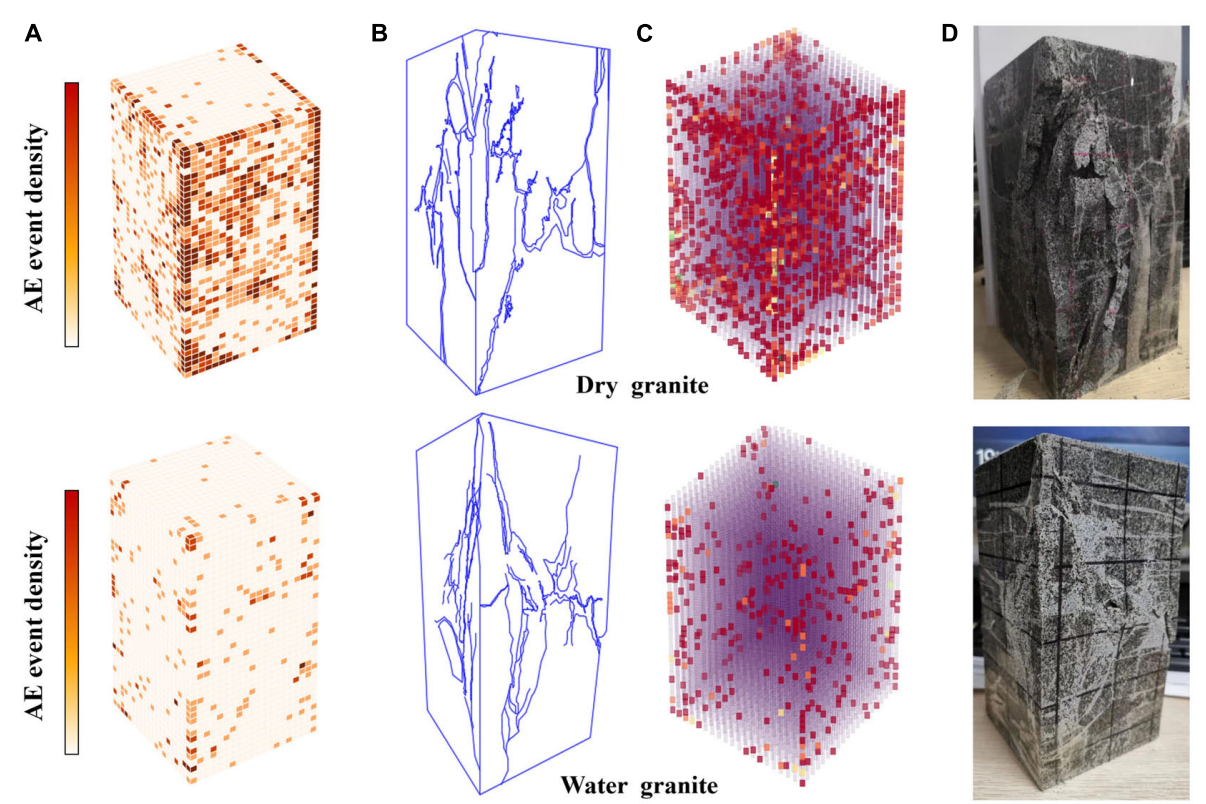

FIGURE 11 | Spatial distribution of AE event density and failure types of saturated water or dry granite are shown, and the density of AE events is directly proportional to the color depth of the cell cube. (A) Surface density distribution of AE event location results; (B) Granite crack growth and fracture mode; (C) Spatial density distribution of AE event location results; (D) Samples. The AE events in the process of granite damage caused by water are significantly reduced. 
Figure 11 shows the positioning results of $\mathrm{AE}$ events using the collaborative localization method using analytical and iterative solutions (Dong et al., 2019). From density distribution of AE events on samples surface and inside, it can be clearly reflected for the inhibit influence of water on the damage difference of granite under uniaxial compression. The spatial location results of $\mathrm{AE}$ events reflect the propagation distribution of the crack and are consistent with the actual failure.

The granite -a typical brittle failure- collapses instantaneously with large huge noise when it reaches peak strength. In the fracture mechanics, cracks are often classified into the opening crack, the sliding mode crack, and the tearing mode crack (Zhao et al., 2019). according to their forces and crack propagation paths. There is no obvious difference between the failure modes of dry and saturated water granite under uniaxial compression. The fracture mode of the uniaxial compression granite sample is composed of the fracture plane parallel to the axial splitting failure plane, the shear failure plane penetrating the whole rock sample, and expansion and fragmentation of local rock. However, from the perspective of the degree of damage, the dry granite is dominated by tensile failure surfaces and the secondary fracture surfaces formed are more abundant; the crack propagation is more sufficient with dense fracture surface; The local brittle expansion and fragmentation of the rock sample is more obvious. Due to the shear slip, the material on the side of the rock sample is broken out and part of the bearing capacity is lost instantly. This kind of failure situation corresponds to the obvious stress drop of the stress-strain curve of dry granite at the peak strength.

\section{CONCLUSION}

(1) The peak strength and elastic modulus of the saturated water granite are decreased, showing obvious plasticity. After uniaxial compression, penetrating shear fracture surface and axial tensile fracture surface was appeared in dry and saturated water granite, and a local comminuted expansive fracture failure occurred. Unlike in the dry state, saturated water granite has better integrity of rock fragmentation that the failure case is fewer surface cracks, smaller localized areas of fragmentation and expansion of rock.

(2) The variation characteristics of $b$ value of dry and saturated water granite are similar in the process of uniaxial compression. The decrease of $b$ value is the precursor of rockburst. However, the changing trend of $b$ value

\section{REFERENCES}

Chen, J. X., Wang, Q. S., Guo, J. Q., Luo, Y. B., Li, Y., Qin, L., et al. (2018). Mechanical properties and acoustic emission characteristics of karst limestone under uniaxial compression. Adv. Mater. Sci. Eng. 2018:2404256. doi: 10.1155/ 2018/2404256

Chen, L., Zhao, J., and Zheng, Z. Y. (2017). Acoustic emission characteristics of compressive deformation and failure of siltstone under different water contents. Adv. Mater. Sci. Eng. 2017:4035487. doi: 10.1155/2017/4035487

Chmel, A., and Shcherbakov, I. (2013). A comparative acoustic emission study of compression and impact fracture in granite. Int. J. Rock Mech. Min. 64, 56-59. doi: 10.1016/j.ijrmms.2013.08.025 of saturated water granite is more gradual with smaller decline, and the internal damage breeding process of hydrated granite is stable.

(3) The cumulative AE events of saturated water granite is less, but the $\mathrm{AE}$ event rate of saturated water granite is higher in the near failure. The AE quiet period of saturated water granite is more obvious, and it enters the quiet period at lower load level and lasts longer. Water significantly inhibit the release of energy in the process of fracture, reduced the proportion of high energy level AE events generated in the critical state, and the rockburst process is more peaceful.

(4) After being softened by water, granite shows obvious plasticity and rockburst tendency is significantly reduced. Water-rock interaction is a complex physical and chemical process. The erosion of rock mass by water can reduce the fracture tendency of brittle rock, but correspondingly increase the potential support burden of surrounding rock.

\section{DATA AVAILABILITY STATEMENT}

The raw data supporting the conclusions of this article are available on request to the corresponding author.

\section{AUTHOR CONTRIBUTIONS}

JM clarified the research purpose, developed the outline of this research, and participated in throughout the experiments, data analysis, and draft preparation. YZ were responsible for manuscript finishing, data processing, and figure plotting. DS completed the experiments and data acquisition. LZ provided the guide of $b$ value theory and calculation procedures for the study. YC provided a figure of the sensor arrangement.

\section{FUNDING}

The authors want to acknowledge the support of projects of the National Natural Science Foundation of China (51774327 and 51904334).

\section{ACKNOWLEDGMENTS}

We are especially grateful to Prof. L. J. Dong of Central South University for his writing suggestions on the manuscript.

Chmel, A., and Shcherbakov, I. (2014). Temperature dependence of acoustic emission from impact fractured granites. Tectonophysics 632, 218-223. doi: $10.1016 /$ j.tecto.2014.06.015

Dong, L. J., Li, X. B., Tang, L. Z., and Gong, F. G. (2011). Mathematical functions and parameters for microseismic source location without pre-measuring speed. Chin. J. Rock Mech. Eng. 30, 2057-2067.

Zhang, Y. B., Liang, P., Liu, X. X., Liu, S. J., and Tian, B. Z. (2015). Experimental study on precursor of rock burst based on acoustic emission signal dominant-frequency and entropy. Chin. J. Rock Mech. Eng. 34, 2959-2967.

Zhang, Z. P., Zhang, R., Xie, H. P., Liu, J. F., and Were, P. (2015). Differences in the acoustic emission characteristics of rock salt compared with granite and marble 
during the damage evolution process. Environ. Earth. Sci. 73, 6987-6999. doi: 10.1007/s12665-015-4406-7

Dong, L. J., Hu, Q. C., Tong, X. J., and Liu, Y. F. (2020a). Velocity-free MS/AE source location method for three-dimensional hole-containing structures. Engineering doi: 10.1016/j.eng.2019.12.01

Dong, L. J., Sun, D. Y., Han, G. J., Li, X. B., Hu, Q. C., and Shu, L. (2020b). “Velocityfree localization of autonomous driverless vehicles in underground intelligent mines," in Proceedings of the IEEE Transactions on Vehicular Technology, Piscataway, NJ. doi: 10.1109/TVT.2020.2970842

Dong, L. J., Sun, D. Y., Li, X. B., Ma, J., Zhang, L. Y., and Tong, X. J. (2018). Interval non-probabilistic reliability of surrounding jointed rockmass considering microseismic loads in mining tunnels. Tunn. Undergr. Space Technol. 81, 326-335. doi: 10.1016/j.tust.2018.06.034

Dong, L. J., and Zhang, L. Y. (2019). $b$-value error analysis of rock fracture acoustic emission. J. Yangtze River Sci. Res. Institute doi: 10.11988/ckyyb.20190430

Dong, L. J., Zou, W., Li, X. B., Shu, W. W., and Wang, Z. W. (2019). Collaborative localization method using analytical and iterative solutions for microseismic/acoustic emission sources in the rockmass structure for underground mining. Eng. Fract. Mech. 210, 95-112. doi: 10.1016/j. engfracmech.2018.01.032

Du, K., Su, R., Tao, M., Yang, C., Momeni, A., Wang, S., et al. (2019). Specimen shape and cross-section effects on the mechanicalproperties of rocks under uniaxial compressive stress. Bull. Eng. Geol. Environ. 78, 6061-6074. doi: 10. 1007/s10064-019-01518-x

Du, K., Tao, M., Li, X. B., and Zhou, J. (2016). Experimental study of slabbing and rockburst induced by true-triaxial unloading and local dynamic disturbance. Rock Mech. Rock Eng. 49, 3437-3453. doi: 10.1007/s00603-016-0990-4

Ge, Z., and Sun, Q. (2018). Acoustic emission (AE) characteristics of granite after heating and cooling cycles. Eng. Fract. Mech. 200, 418-429. doi: 10.1016/j. engfracmech.2018.08.011

Goodman, R. E. (1963). Subaudible noise during compression of rocks. Geol. Soc. Am. Bull. 74, 487-490.

Guo, J., Feng, G. R., Qi, T. Y., Wang, P., Yang, J., Li, Z., et al. (2018). Dynamic mechanical behavior of dry and water saturated igneous rock with acoustic emission monitoring. Shock Vib. 2018:2348394. doi: 10.1155/2018/2348394

Hao, R., Jiang-teng, L., and Ping, C. (2015). Test of subcritical crack growth and fracture toughness under water-rock interaction in three types of rocks. J. Cent. South Univ. 22, 662-668. doi: 10.1007/s11771-015-2568-9

Hu, Q. C., and Dong, L. J. (2019). Acoustic emission source location and experimental verification for two-dimensional irregular complex structure. IEEE Sens. J. 20, 2679-2691. doi: 10.1109/JSEN.2019.2954200

Li, A. Q., Zhang, R., Ai, T., Gao, M. Z., Zhang, Z. T., Jing, X., et al. (2016). Acoustic emission space-time evolution rules and failure precursors of granite under uniaxial compression. Chin. J. Geotechn. Eng. 38, 306-311.

Li, S. Y., He, T. M., and Yin, X. C. (2010). Introduction of Rock Fracture Mechanics. HeFei: University of Science and Technology of China Press.

Liu, D. Q., Wang, Z., Zhang, X. Y., Wang, Y., Zhang, X. L., Dong, L., et al. (2018). Experimental investigation on the mechanical and acoustic emission characteristics of shale softened by water absorption. J. Nat. Gas. Sci. Eng. 50, 301-308. doi: 10.1016/j.jngse.2017.11.020

Liu, X. L., Pan, M. C., Li, X. B., and Wang, J. P. (2017). Acoustic emission $b$-value characteristics of granite under dynamic loading and static loading. Chin. J. Rock Mech. Eng. 1, 3148-3155.

Liu, X. R., Fu, Y., Zheng, Y. R., and Liang, N. H. (2012). A review on deterioration of rock caused by water-rock interaction. Chin. J. Undergr. Space Eng. 1, 77-82.

Meng, Q. B., Zhang, M. W., Han, L. J., Pu, H., and Nie, T. Y. (2016). Effects of acoustic emission and energy evolution of rock specimens under the uniaxial cyclic loading and unloading compression. Rock Mech. Rock Eng. 49, 3873-3886. doi: 10.1007/s00603-016-1077-y

Naoi, M., Chen, Y., Nishihara, K., Yamamoto, K., Yano, S., Shota, W., et al. (2018). Monitoring hydraulically-induced fractures in the laboratory using acoustic emissions and the fluorescent method. Int. J. Rock Mech Min. 104, 53-63. doi: 10.1016/j.ijrmms.2018.02.015

Pei, J. L., Liu, J. F., Zuo, J. P., and Zhang, R. (2013). Investigation on dynamic evolution process of natural fractures based on acoustic emission position. Chin. J. Rock Mech. Eng. 32, 696-704.

Peng, K., Liu, Z. P., Zou, Q. L., Wu, Q. H., and Zhou, J. Q. (2020). Mechanical property of granite from different buried depths under uniaxial compression and dynamic impact: an energy-based investigation. Powder Technol. 362, 729-744. doi: 10.1016/j.powtec.2019.11.101
Peng, K., Zhou, J., Zou, Q., and Yan, F. (2019). Deformation characteristics of sandstones during cyclic loading and unloading with varying lower limits of stress under different confining pressures. Int. J. Fatigue. 127, 82-100. doi: 10.1016/j.ijfatigue.2019.06.007

Rao, M., and Lakshmi, K. P. (2005). Analysis of b-value and improved b-value of acoustic emissions accompanying rock fracture. Curr. Sci. India 89, 1577-1582.

Rudajev, V., Vilhelm, J., and Lokajı icek, T. (2000). Laboratory studies of acoustic emission prior to uniaxial compressive rock failure. Int. J. Rock Mech. Min. 37, 699-704. doi: 10.1016/S1365-1609(99)00126-4

Sagasta, F., Zitto, M. E., Piotrkowski, R., Benavent-Climent, A., Suarez, E., and Gallego, A. (2018). Acoustic emission energy $b$-value for local damage evaluation in reinforced concrete structures subjected to seismic loadings. Mech. Syst. Signal Process. 102, 262-277. doi: 10.1016/j.ymssp.2017.09.022

Sirdesai, N. N., Gupta, T., Singh, T. N., and Ranjith, P. G. (2018). Studying the acoustic emission response of an Indian monumental sandstone under varying temperatures and strains. Constr. Build. Mater. 168, 346-361. doi: 10.1016/j. conbuildmat.2018.02.180

Vásárhelyi, B., and Ván, P. (2006). Influence of water content on the strength of rock. Eng. Geol. 84, 70-74. doi: 10.1016/j.enggeo.2005.11.011

Wan, L. H., Cao, P., Huang, Y. H., and Wang, Y. X. (2010). Study of subcritical crack growth of rocks and threshold values in different environments. Chin. J. Rock Soil Mech. 31, 2737-2742.

Wang, M. M., and Xiao, L. H. (2018). The $b$-value analysis of bedded shale under cyclic loading experiments. J. Geophys. Eng. 15, 1291-1299. doi: 10.1088/17422140/aaaf48

Wang, Q. S., Chen, J. X., Guo, J. Q., Luo, Y. B., Wang, H. Y., Qing, L., et al. (2017). Acoustic emission characteristics and energy mechanism in karst limestone failure under uniaxial and triaxial compression. B. Eng. Geol. Environ. 78, 1427-1442. doi: 10.1007/s10064-017-1189-y

Zeng, Z. W., Ma, J., Liu, L. Q., and Liu, T. C. (1995). Acoustic emission $b$-value dynamic features during rock mass fracturing and their sicnificances. Seismol. Geol. 1, 7-12.

Zhang, Q., and Zhang, X. P. (2017). A numerical study on cracking processes in limestone by the b-value analysis of acoustic emissions. Comput. Geotech. 92, 1-10. doi: 10.1016/j.compgeo.2017.07.013

Zhang, Y. B., Liang, P., Liu, X. X., and Tian, B. Z. (2017). Experimental study on the effect of acoustic emission quiet period of granite with water-saturated. Chin. J. Undergr. Space Eng. 13, 598-605.

Zhang, Y. B., Liang, P., Sun, L., Tian, B. Z., and Yao, X. L. (2019). Spectral characteristics of acoustic emission in the process of saturated granite fracture under uniaxial compress. Chin. J. Rock Soil Mech. 40, 2497-2506.

Zhao, G. Y., Dai, B., Dong, L. J., and Cheng, Y. (2015). Energy conversion of rocks in process of unloading confining pressure under different unloading paths. Trans. Nonferr. Met. Soc. China. 25, 1626-1632. doi: 10.1016/S1003-6326(15) 63767-0

Zhao, X. D., Liu, J. P., Li, Y. H., Tian, J., and Zhu, W. C. (2008). Experimental verification of rock locating technique with acoustic emission. Chin. J. Geotechn. Eng. 30, 1472-1476.

Zhao, X. D., Tang, C. A., Li, Y. H., Yuan, R. F., and Zhang, J. Y. (2006). Study on acoustic emission activity characteristics under uniaxial compression loading. Chin. J. Rock Mech. Eng. 25, 3673-3678.

Zhao, Y. L., Wang, Y. X., and Tang, L. M. (2019). The compressive-shear fracture strength of rock containing water based on druker- prager failure criterion. Arab. J. Geosci. 12:452.

Zhao, Y. L., Zhang, L. Y., Wang, W. J., Tang, J. Z., Lin, H., and Wan, W. (2017). Transient pulse test and morphological analysis of single rock fractures. Int. J. Rock Mech. Min. 91, 139-154. doi: 10.1016/j.ijrmms.2016. 11.016

Conflict of Interest: The authors declare that the research was conducted in the absence of any commercial or financial relationships that could be construed as a potential conflict of interest.

Copyright $\odot 2020$ Zhang, Ma, Sun, Zhang and Chen. This is an open-access article distributed under the terms of the Creative Commons Attribution License (CC BY). The use, distribution or reproduction in other forums is permitted, provided the original author(s) and the copyright owner(s) are credited and that the original publication in this journal is cited, in accordance with accepted academic practice. No use, distribution or reproduction is permitted which does not comply with these terms. 